Review

\title{
Environmental Pollution and Chronic Kidney Disease
}

\author{
Hui-Ju Tsai1 ${ }^{1,2,3,4}$, Pei-Yu Wu 5,6, Jiun-Chi Huang ${ }^{5,6,7}$, Szu-Chia Chen ${ }^{4,5,6,7 凶}$ \\ 1. Department of Family Medicine, Kaohsiung Municipal Ta-Tung Hospital, Kaohsiung Medical University Hospital, Kaohsiung Medical University, \\ Kaohsiung, Taiwan \\ 2. Department of Family Medicine, School of Medicine, College of Medicine, Kaohsiung Medical University, Kaohsiung, Taiwan \\ 3. Graduate Institute of Clinical Medicine, College of Medicine, Kaohsiung Medical University, Kaohsiung, Taiwan \\ 4. Research Center for Environmental Medicine, Kaohsiung Medical University, Kaohsiung, Taiwan \\ 5. Division of Nephrology, Department of Internal Medicine, Kaohsiung Medical University Hospital, Kaohsiung Medical University, Kaohsiung, Taiwan \\ 6. Department of Internal Medicine, Kaohsiung Municipal Siaogang Hospital, Kaohsiung Medical University, Kaohsiung, Taiwan \\ 7. Faculty of Medicine, College of Medicine, Kaohsiung Medical University, Kaohsiung, Taiwan
}

$\triangle$ Corresponding author: Szu-Chia Chen. Department of Internal Medicine, Kaohsiung Municipal Hsiao-Kang Hospital, Kaohsiung Medical University, Kaohsiung, Taiwan, 482, Shan-Ming Rd., Hsiao-Kang Dist., 812 Kaohsiung, Taiwan, R.O.C. TEL: 886- 7- 8036783 - 3441; FAX: 886- 7- 8063346; E-mail: scarchenone@yahoo.com.tw

(c) The author(s). This is an open access article distributed under the terms of the Creative Commons Attribution License (https://creativecommons.org/licenses/by/4.0/). See http://ivyspring.com/terms for full terms and conditions.

Received: 2020.08.06; Accepted: 2020.12.17; Published: 2021.01.01

\begin{abstract}
Chronic kidney disease (CKD) is a global public health problem associated with high rates of morbidity and mortality due to end-stage renal disease and cardiovascular disease. Safe and effective medications to reverse or stabilize renal function in patients with CKD are lacking, and hence it is important to identify modifiable risk factors associated with worsening kidney function. Environmental pollutants, including metals, air pollutant, phthalate and melamine can potentially increase the risk of CKD or accelerate its progression. In this review, we discuss the epidemiological evidence for the association between environmental pollution and kidney disease, including heavy metals, air pollution and other environmental nephrotoxicants in the general population.
\end{abstract}

Key words: chronic kidney disease; environmental pollution; heavy metal

\section{Introduction}

Chronic kidney disease (CKD) is a global public health issue [1-3]. The reported prevalence of CKD is $11.9 \%$ in Taiwan [4], and it has gradually increased over the past decade resulting in a large economic burden on the National Health Insurance program. CKD is defined as either a reduced glomerular filtration rate (GFR $<60 \mathrm{~mL} / \mathrm{min} / 1.73 \mathrm{~m} 2$ ) or evidence of kidney damage such as an abnormal pathology or albuminuria for at least 3 months. CKD is one of the ten leading causes of death in Taiwan, and these patients have a higher risk of progression to dialysis and cardiovascular mortality. According to the US Renal Data System [5], the prevalence and incidence of CKD and end-stage renal disease (ESRD) in Taiwan are among the highest in the world.

The pathophysiology and mechanisms of worsening renal function are complex and multifactorial. In addition to the well-known risk factors for renal injury, such as aging, diabetes mellitus and hypertension, some environmental chemicals have also been shown to be important risk factors for renal injury [6-10]. With the ever increasing use of synthetic compounds in all aspects of daily life, the risk to health of environmental toxins and pollutants becomes increasingly important. In particular, as the kidneys are responsible for excreting waste products from the body they are exposed to toxins and pollutants in the blood, and they are therefore susceptible to the adverse effects stemming from this exposure.

In this review, we summarize the current data regarding environmental exposure to toxins and pollutants and kidney disease. Environmental nephrotoxicants can be classified as follows: (1) metals, (2) air pollution, and (3) other non-metal exposure. We searched the PubMed (http:/ / www.ncbi.nlm.nih.gov/pubmed) database to find published studies from January 1988 to June 2020 that investigated the relationships between environmental exposure to toxins and pollutants and 
CKD and/or markers of kidney injury. We performed the search using the following terms: 'environmental pollution and chronic kidney disease', 'environmental pollution and proteinuria', 'environmental pollution and albuminuria', 'environmental exposure and chronic kidney disease', 'environmental exposure and proteinuria', 'environmental exposure and albuminuria', 'air pollution and chronic kidney disease' , 'air pollution and proteinuria', 'air pollution and albuminuria, 'metals and chronic kidney disease', 'metals and proteinuria', 'metals and albuminuria'. The search was limited to research articles involving humans and those published in English. Unpublished data and abstracts were not included in this review.

\section{Metals}

Metals are common environmental pollutants that have been associated with impaired kidney function in many epidemiological studies. Metals used in industrial processes have been shown to contaminate drinking water, food and soil, thereby increasing the risk of exposure among the general population. In the following sections, we summarize the metals that are known to have a nephrotoxic effect, including arsenic, cadmium, lead, mercury and uranium.

\section{Arsenic}

Arsenic (As) is a highly toxic metalloid that occurs ubiquitously in the environment [11]. Environmental sources of As include contaminated drinking water, pesticides, seafood, folk or alternative remedies, and products used for wood preservation [7]. Acute As-induced renal intoxication has been shown to lead to acute tubular necrosis and tubulointerstitial nephritis [11, 12]. In addition, chronic exposure to As has been associated with the development and progression of CKD due to As-induced oxidative stress [11, 13].

Exposure to As through the environment, occupation and diet has been reported to cause renal injury and the development of renal disease [11, 14, 15]. A prospective observational study in Taiwan reported that people ingesting $\geq 50 \mu \mathrm{g} / \mathrm{L}$ of As in well water had a 30\% increased risk of clinically recognized CKD compared to $\leq 10 \mu \mathrm{g} / \mathrm{L}$ [16]. In addition, a community-based cross-sectional study conducted in central Taiwan reported that the risk for eGFR $<90 \mathrm{~mL} / \mathrm{min} / 1.73 \mathrm{~m}^{2}$ was increased by around 2-fold in people with a urine As level $>75 \mu \mathrm{g} / \mathrm{g}$ creatinine compared to those with a urine As level $\leq$ $35 \mathrm{\mu g} / \mathrm{g}$ creatinine [17]. Moreover, Cheng et al. conducted another study in Taiwan including 8854 adults from a nationwide health screening program from 2000 to 2009 [18]. They found that $>50 \mu \mathrm{g} / \mathrm{L}$ of
As in drinking water was associated with an odds ratio (OR) of 1.22 (95\% confidence interval [CI]: 1.051.42) for the rapid progression of CKD (eGFR decline $>5 \mathrm{ml} / \mathrm{min} / 1.73 \mathrm{~m}^{2} /$ year). Another cross-sectional study conducted in China also found that a plasma As concentration $>0.93 \mu \mathrm{g} / \mathrm{L}$ was associated with eGFR $<60 \mathrm{~mL} / \mathrm{min} / 1.73 \mathrm{~m}^{2}$ [19]. In addition, Liu et al. conducted a prospective cohort and reported that a plasma As concentration > $3.16 \mu \mathrm{g} / \mathrm{L}$ was significantly associated with an annual decline in eGFR among Chinese adults [20].

\section{Cadmium}

Cadmium (Cd) is known to be nephrotoxic environmental pollutant $[7,21]$. Cd has a long half-life in the body, ranging from 7.4 to 16 years [11, 22]. High levels of exposure can result in the accumulation of $\mathrm{Cd}$ in the proximal tubules of the kidney, and this has been shown to impair tubular function and protein reabsorption [23]. In the general population, tobacco smoking is a main source of Cd exposure [24-26], and in non-smokers exposure commonly occurs from dietary intake of contaminated food and water [27]. Occupational $\mathrm{Cd}$ exposure includes battery manufacturing, pigments, coatings, plastics, and copper and zinc smelting and welding [28]. Urinary $\mathrm{Cd}$ is considered to be the most accurate measure of long-term exposure, whereas blood $\mathrm{Cd}$ is considered to be a measure of more recent exposure, such as exposure within the past month [8].

Clinically, Cd nephrotoxicity presents with symptoms including low molecular weight proteinuria, glucosuria, aminoaciduria, low molecular weight proteinuria, hypercalciuria and renal stones [8]. Urinary Cd levels of $4-10 \mu \mathrm{g} / \mathrm{g}$ creatinine have been associated with increased microalbuminuria [29]. Accordingly, the US Occupational Safety and Health Administration and World Health Organization $(\mathrm{WHO})$ define the safe standard to be a urinary $\mathrm{Cd}$ concentration of $<3 \mu \mathrm{g} / \mathrm{g}$ and $5.24 \mu \mathrm{g} / \mathrm{g}$ creatinine, respectively [30]. Increasing evidence has shown that chronic exposure to $\mathrm{Cd}$ is associated with reduced GFR and an increased risk of CKD [31]. Two cross-sectional studies indicated that urinary $\mathrm{Cd}$ was significantly positively associated with renal tubule biomarkers including $\mathrm{N}$-acetyl- $\beta$-D-glucosaminidase and $\beta 2$-microglobulin in the general population in China and Korea [32, 33]. In addition, blood Cd concentration has been associated with kidney function in US adults [34, 35]. Madrigal et al. analyzed US National Health and Nutrition Examination Survey (NHANES) data from 2007-2012, and demonstrated that blood $\mathrm{Cd}$ concentration was positively associated with elevated albumin excretion in urine and inversely associated with eGFR. In their 
study, a stronger association was found between impaired kidney function and blood $\mathrm{Cd}$ concentration in the female participants compared to the male participants, and the association also differed according to hypertension [36]. These findings are consistent with two studies using Korean NHANES $[37,38]$.

\section{Lead}

Lead $(\mathrm{Pb})$ is found throughout the environment, primarily due to human activity. $\mathrm{Pb}$ compounds are commonly used in gasoline, batteries, pipes, ammunition, paints, ceramic glazes, water contaminated by $\mathrm{Pb}$ pipes, food contaminated during processing, Pb-adulterated alcohol, and other industrial applications [11]. Pb circulates in the blood, and it is either excreted by the kidneys or accumulates in bone. The half-life of $\mathrm{Pb}$ in the blood is around 35 days, compared to 10-30 years in bone [7].

$\mathrm{Pb}$ is the most common environmental nephrotoxicant, and exposure can cause oxidative stress in tubular and glomerular cells and lead to the generation of free radicals, potentially contributing to cellular apoptosis and subsequent changes in renal structure and function [39]. Acute $\mathrm{Pb}$ toxicity (blood $\mathrm{Pb}$ level $>80-100 \mu \mathrm{g} / \mathrm{dL}$ ) has been reported to cause proximal tubular injury, possibly due to cytoplasmic, mitochondrial and intranuclear inclusion bodies composed of $\mathrm{Pb}$-protein complexes [40], and the clinical manifestations include glucosuria, aminoaciduria, phosphaturia, and Fanconi syndrome [41]. Chronic $\mathrm{Pb}$ poisoning (blood $\mathrm{Pb}$ level $>60$ $\mu \mathrm{g} / \mathrm{dL}$ ) has been reported to cause $\mathrm{Pb}$ nephropathy, which is characterized by glomerular sclerosis, tubular atrophy, tubulointerstitial fibrosis, and finally reduced GFR $[41,42]$. In addition, chronic low $\mathrm{Pb}$ exposure (blood $\mathrm{Pb}$ level $<5-10 \mathrm{mg} / \mathrm{dL}$ ) has been reported to potentially contribute to the development of CKD and the progression of established CKD [43-45]. The association between body $\mathrm{Pb}$ level and CKD has also been reported to be affected by age, sex, diabetes, hypertension, and uric acid level [46].

Two cross-sectional studies analyzed the US NHANES from 1999 to 2002 and 1999 to 2006 [35, 47], and found that even low blood Pb levels may be associated with CKD. In the US NHANES 1999 to 2002, the prevalence of CKD among adults was found to be higher in those with higher blood $\mathrm{Pb}$ levels. The adjusted ORs of prevalent CKD increased with increasing quartiles of blood $\mathrm{Pb}$ level $(\mathrm{Q} 1<1.06$ $\mathrm{mg} / \mathrm{dL}, \mathrm{Q} 2=1.06-1.63 \mathrm{mg} / \mathrm{dL}, \mathrm{Q} 3=1.63-2.7 \mathrm{mg} / \mathrm{dL}$, $\mathrm{Q} 4 \geq 2.47 \mathrm{mg} / \mathrm{dL})(\mathrm{OR}=1.49,95 \% \mathrm{CI}=0.75-2.98 ; \mathrm{OR}=$ $1.89,95 \% \mathrm{CI}=1.09-3.30$; and $\mathrm{OR}=2.72,95 \% \mathrm{CI}=$ 1.47-5.04, respectively, for the second, third, and fourth quartiles) [47]. Another analysis of the US
NHANES 1999 to 2006 reported that among adults with a blood $\mathrm{Pb}$ level $>2.4 \mathrm{mg} / \mathrm{dL}$, the $\mathrm{OR}$ for prevalent $\mathrm{CKD}$ was $1.56(95 \% \mathrm{CI}=1.17-2.08)$ compared to adults with a blood Pb level $\leq 1.1 \mathrm{mg} / \mathrm{dL}$ [35]. In addition, a NHANES from 2007 to 2012 demonstrated that a positive association between urine $\mathrm{Pb}$ level and an inverse association between blood Pb level and eGFR [34]. Similarly, a cross-sectional study of Korean adults reported a positive association between blood $\mathrm{Pb}$ levels and renal dysfunction [48].

An increasing number of longitudinal studies have supported that $\mathrm{Pb}$ exposure contributes to an increased risk of kidney disease. Yu et al. explored the association between low-level environmental $\mathrm{Pb}$ exposure and renal function among 121 patients with non-diabetic CKD in Taiwan [49]. After 4 years, every increase of $1 \mathrm{mg} / \mathrm{dL}$ in blood $\mathrm{Pb}$ level at baseline was associated with a decrease in GFR of $4.0 \mathrm{~mL} / \mathrm{min} / 1.73$ $\mathrm{m}^{2}$ [49]. In addition, a prospective population-based study conducted in Sweden investigated the association between low levels of $\mathrm{Pb}$ exposure and kidney function among 2567 participants who completed follow-up [50]. Their results showed that the change in eGFR was higher in the participants in the third and fourth quartiles of blood $\mathrm{Pb}$ level (median concentrations of 29 and $46 \mu \mathrm{g} / \mathrm{L}$, respectively) compared to those in the lowest quartiles [50]. Moreover, the participants in the highest quartile of blood $\mathrm{Pb}$ level had a $49 \%$ increased risk of incident CKD compared to those in the three lower quartiles [50].

Several studies have explored the relationship between environmental $\mathrm{Pb}$ exposure and nephrolithiasis. Hara et al. recruited 1302 Flemish participants and reported that environmental $\mathrm{Pb}$ exposure was a risk factor for nephrolithiasis [51]. In addition, a study of participants from five consecutive US NHANES 2-year cycles (2007-2016) showed that blood $\mathrm{Pb}$ level was associated with the risk of kidney stones in adults [52].

\section{Mercury}

Exposure to mercury (Hg) compounds occurs via occupational, dietary and environmental sources, including contaminated water, fresh water fish from a contaminated source, predatory ocean fish, gold mining, smelting, burning fuel, incineration and whitening creams $[7,53]$. $\mathrm{Hg}$ exists in elemental, inorganic, and organic forms, all of which are nephrotoxic [11]. Hg exposure occurs through oral, inhalation, and dermal routes, however the most common route is through the consumption of foods contaminated with $\mathrm{Hg}$ including seafood [8].

$\mathrm{Hg}$ readily accumulates in the kidneys and can 
contribute to both tubular and glomerular damage $[54,55]$. The pars recta of proximal tubules has been reported to be most sensitive to $\mathrm{Hg}$, and it is usually the first nephron segment to be affected by exposure to $\mathrm{Hg}$ compounds [56]. After filtration, $\mathrm{Hg}$ is reabsorbed by the proximal tubules, resulting in tubular toxicity presenting as low molecular weight proteinuria and enzymuria. $\mathrm{Hg}$ has been associated with CKD progression $[44,57,58]$. In addition, clinical reports have suggested that $\mathrm{Hg}$ exposure can cause various renal manifestations including membranous glomerulopathy, interstitial nephritis, acute tubular necrosis and interstitial nephritis, or a minimal change in disease with nephrotic syndrome [59]. In a study of adults in the US NHANES 2003-2004, Lin et al. reported a higher adjusted OR of reduced GFR $(<60$ $\left.\mathrm{mL} / \mathrm{min} / 1.73 \mathrm{~m}^{2}\right)$ with increasing tertiles of blood $\mathrm{Hg}$ level $(\mathrm{OR}=2.09[95 \% \mathrm{CI}=1.11-3.96]$ and $2.94[95 \% \mathrm{CI}$ = 1.04-8.33] for tertile 2 [blood $\mathrm{Hg}$ level 0.66-1.64 $\mathrm{mg} / \mathrm{L}$ ] and tertile 3 [blood $\mathrm{Hg}$ level $>1.64 \mathrm{mg} / \mathrm{L}$ ], respectively), compared with the lowest tertile (blood $\mathrm{Hg}<0.66 \mathrm{mg} / \mathrm{L}$ ). In addition, Nuyts et al. conducted a case-control study of occupational exposure to $\mathrm{Hg}$ in 272 patients with CKD and 272 controls matched for age, sex and area of residence, and found that $\mathrm{Hg}$ exposure was independently associated with an increased risk of $\mathrm{CKD}(\mathrm{OR}=5.13,95 \% \mathrm{CI}=1.02-25.7)$ [60] However, a recent study of artisanal gold miners who were exposed to $\mathrm{Hg}$ vapor did not find an association between increased urinary $\mathrm{Hg}$ concentration and reduced eGFR [61]. Kim et al. conducted a cross-sectional study of the Korean NHANES from 2008-2010, and reported that blood $\mathrm{Hg}$ levels, which reflect organic $\mathrm{Hg}$ exposure rather than inorganic $\mathrm{Hg}$ exposure, did not show a significant inverse association with eGFR after adjustments [48].

\section{Uranium}

Environmental exposure to uranium (U) is mainly through the ingestion of contaminated groundwater, soil, and food [6]. Occupational exposure also may occur through inhalation. U toxicity primarily occurs in the kidneys. Complexed U dissociates at a lower $\mathrm{pH}$ to release the reactive uranyl ion, which can interact with proximal tubule membranes. Urine is the primary means of quantifying exposure to $U$ as most absorbed $U$ is excreted in the urine within several weeks [8]. The most frequently used standard for $U$ kidney burden is the International Commission on Radiological Protection value of $3 \mu \mathrm{g} / \mathrm{g}$ [62].

Oral exposure to $U$ from drinking contaminated water and occupational exposure have been associated with glucosuria, aminoaciduria, microal- buminuria, $\beta 2$ microglobulinuria, phosphaturia, and hypercalciuria [63-66]. Okaneku et al. demonstrated an association between urinary $\mathrm{U}$ (median $=0.009$ $\mathrm{ug} / \mathrm{L}$ ) and moderate albuminuria, but no association with a decrease in kidney function [65]. Wu et al. analyzed 934 hypertensive patients in China and found an inverse association between $U$ level and eGFR in the overall population, and the association was stronger among women with high chromium exposure [67]. Several studies have reported an association between exposure to $\mathrm{U}$ and kidney injury, but without statistical significance $[68,69]$.

\section{Air pollution}

Particulate matter (PM) is a mixture of suspended liquid and solid particles in the air. It is a common air pollutant which varies widely in terms of size and chemical composition [70]. PM is mostly composed of nitrates, sulfates, ammonium, other inorganic ions and metals, and may also involve biological agents such as allergens and microbial substances [71]. The common health-related concerns of PM involve particles with a diameter $<10 \mu \mathrm{m}$ (PM10) and $2.5 \mu \mathrm{m}$ (PM2.5).

Increasing epidemiologic evidence suggests that PM is a risk factor for CKD [72]. Studies in the US have reported that PM air pollution leads to a decline in GFR and is associated with the prevalence and incidence of CKD [73-76] Studies in Taiwanese and Korean adults have also observed associations between higher PM air pollution levels and reduced renal function, an increased risk of developing CKD, and the incidence of nephrotic syndrome [77-79]. In addition, Mehta et al. investigated the association between longitudinal changes in eGFR and long-term exposure to PM2.5 in 669 older men. Their results showed that a $2.1 \mu \mathrm{g} / \mathrm{m} 3$ interquartile range higher 1-year exposure to PM2.5 was associated with a 1.87 $\mathrm{mL} / \mathrm{min} / 1.73 \mathrm{~m} 2$ lower eGFR and an additional annual decrease in eGFR of $0.60 \mathrm{~mL} / \mathrm{min} / 1.73 \mathrm{~m}^{2}$ per year [76]. Moreover, Chan et al. conducted a study from 2001-2014 with 100,629 Taiwanese residents without CKD aged $>20$ years, and found that every 10 $\mu \mathrm{g} / \mathrm{m}^{3}$ increase in PM2.5 concentration was associated with a $6 \%$ increased risk of developing CKD (hazard ratio $=1.06,95 \% \mathrm{CI}=1.02,1.10$ ) [77].

Few studies have examined the association between PM and the progression of CKD in patients with kidney damage $[74,80]$. Bowe et al. demonstrated a significant association between PM2.5 concentration and the risk of developing kidney disease and progression to ESRD in an observational cohort of 2,482,737 US veterans [74]. Another study from Hong Kong reported a positive association between annual exposure to PM2.5 and mortality 
from ischemic heart disease among older patients with CKD [80]. In addition, a nationwide, multicenter, prospective cohort of Korean ESRD patients indicated that increased exposure to PM10 from 1 to 7 years increased the risk of mortality, and that long-term exposure to $\mathrm{NO}_{2}$ and $\mathrm{SO}_{2}$ was a significant risk factor for mortality due to ESRD regardless of the length of exposure [81]. Moreover, experimental laboratory evidence has shown that exhaust particle exposure can lead to changes in hemodynamics in the kidneys, induce oxidative stress, inflammation, and DNA damage in renal tissues, worsen acute kidney injury, and further promote chronic renal injury in murine models $[82,83]$.

In summary, experimental and clinical findings indicate the biologic plausibility and support the hypothesis that environmental exposure to elevated levels of PM2.5 is associated with an increased risk of kidney disease. More evidence from a variety of regions and populations is needed to clarify the effects of PM on renal health. These findings support the global strategy to reduce air pollution and prevent the development of CKD.

\section{Other non-metals}

\section{Phthalates}

In 2011, a major health scandal involving phthalate-tainted foodstuffs occurred in Taiwan [84-90]. Phthalates, and mainly di-(2-ethylhexyl) phthalate (DEHP) and/or di-isononyl phthalate (DINP) were intentionally added to foodstuffs as a substitute for emulsifiers, particularly in nutrient supplements and probiotics regularly taken by children [84-90]. In addition, phthalates are commonly added to cosmetics as a solvent for fragrance and to many other commonly used products such as paint, toys, and medical devices to make them soft and flexible. Another main source of exposure to phthalates in the general population is from plastic containers or plastic bags exposed to high temperatures, and the use of plastic materials during food production [91, 92]. Therefore, humans are potentially exposed to phthalates via inhalation, absorption through the skin, or ingesting food.

Recent studies have investigated the relationship between phthalate exposure and renal function including early renal injury markers such as urine albumin/creatinine ratio and urinary $\beta 2$-microglobulin $(\beta 2 \mathrm{M})$ in different populations. Trasande and colleagues investigated the relationship between exposure to phthalates and renal function in 667 children aged 6-19 years who participated in the 2009-2010 NHANES by measuring metabolites in their urine [93]. They found that certain metabolites of high molecular weight phthalates such as DEHP in urine were significantly and positively associated with urine albumin to creatinine ratio (ACR), which is regarded to be a clinical marker of glomerular injury. After the scandal of phthalate-tainted foodstuffs in Taiwan, Tsai et al. reported a possible association between DEHP and an increase in microalbuminuria in children who consumed higher amounts of foods contaminated with phthalates [88]. Chen et al. also reported associations between some DEHP metabolites and benzyl butyl phthalate and impaired renal function in 1663 adults in the 2012 Shanghai Food Consumption Survey [94]. The same authors used principal component analysis to examine associations between the patterns of exposure and impaired renal function, and found positive associations between high molecular weight phthalate pattern score and renal function parameters (ACR, $\beta 2 \mathrm{M}$, and $\mathrm{N}$-acetyl b-D-glucosaminidase [NAG]), which is consistent with the results of single metabolite analyses [95]. In addition, a study of healthy Korean female adults revealed a significant positive association between exposure to mono-n-butyl phthalate (MnBP) and urine ACR with a dose-response relationship [96]. In addition, a cross-sectional study of Italian patients with diabetes mellitus revealed an association between exposure to DEHP metabolites including mono-(2-ethylhexyl) phthalate (MEHP) and mono-(2-ethyl-5-oxohexyl) phthalate (MEOHP) and the degree of albuminuria, however no association with eGFR was noted [97]. In contrast, Malits et al. used a cross-sectional study design to compare the Chronic Kidney Disease in Children Study and NHANES 2007-2008, and found that children aged 1 to 17 years with CKD had not been exposed to increased levels of phthalates [98]. In summary, several cross-sectional studies have suggested that phthalates may be associated with renal injury markers. Further longitudinal research is needed to clarify the causal relationship.

\section{Melamine}

Melamine is a synthetic organic base used in many commercial products including dry erases boards, cleaning supplies, and other plastic goods. Despite the 2008 melamine baby formula scandal in China which resulted in kidney-related disease in children [99], melamine is still widely present in the environment and is detected in most urine samples obtained from the general populations of the USA and Taiwan [100, 101]. A series of epidemiological studies support the hypothesis that long-term environmental exposure to low-dose melamine can increase the risk of adverse kidney outcomes, including urolithiasis, early renal damage, and the deterioration of kidney 
function in adults [102-106]. Liu et al reported that chronic low-dose melamine exposure was associated with an increase in the risk of calcium urolithiasis formation in Taiwanese adults [102, 103], and urinary melamine has been significantly associated with NAG in urolithiasis patients, especially those with a first stone episode [105]. In addition, $\mathrm{Wu}$ et al. reported a positive association between urinary melamine levels and urinary NAG levels, and that the detectable rate of $\beta 2 \mathrm{M}$ was increased in workers in melamine tableware manufacturing factories [104]. Moreover, Tsai et al. conducted a prospective cohort study including patients with an eGFR $\geq 30 \mathrm{ml} / \mathrm{min} / 1.73 \mathrm{~m}^{2}$ from 2006 to 2010 in Taiwan, and found that urinary melamine level was significantly associated with deterioration in kidney function in patients with early-stage CKD [106]. Furthermore, Jianqiu et al. analyzed associations between melamine and cyanuric acid exposure and markers of kidney function in adults from the NHANES 2003-2004 [107]. They found that adults who had exposed to high levels of melamine had a lower eGFR than those who had been exposed to low levels of melamine, although there were no significant associations between melamine and cyanuric acid exposure and markers of kidney function [107]. In addition, a cross-sectional study of 109 children (aged 4 months to 8 years) in the USA suggested that cyanuric acid, which is a structural analogue of melamine, was associated with increased kidney injury molecule-1 (KIM 1) concentrations [108].

Melamine has been shown to crystallize in distal renal tubules, and this may explain the reported cases of nephrolithiasis and acute kidney injury. It has also been hypothesized that melamine-induced oxidative stress contributes to renal tubular injury [109, 110]. Further prospective cohort studies are needed to clarify the causal effect of environmental low-dose melamine exposure and adverse kidney outcomes in patients with stones and the detailed mechanisms leading to the adverse effects.

\section{Bisphenol A}

Bisphenol A (BPA) is a synthetic chemical comprised of two phenol rings connected by a methyl bridge, to which two methyl groups are attached. Environmental BPA exposure can occur via absorption through the skin, ingestion and respiration, and detectable levels of BPA have been reported in the urine of $>93 \%$ of adults [111], with high serum levels among men and smokers [112].

Previous studies have reported inconsistent associations between BPA and kidney function. Urinary BPA levels have been positively associated with ACR among US children [113] and Chinese adults [114]. In addition, a positive association between urinary BPA levels and eGFR was found among a general population of US adult females, but not in adult males who participated in NHANES 2003-2006 [115]. In contrast, no associations between urinary BPA and eGFR or urine protein to creatinine ratio (PCR) or urine ACR were found among US children with CKD [98] and Korean healthy women [96]. Positive associations between serum BPA level and CKD have been reported in several prospective studies of patients with type 2 diabetes [116, 117]. Different characteristics of the studied populations among these published studies may at least partially explain the discrepancies in the findings.

\section{Conclusion}

Environmental pollutants including heavy metals, PM, and other chemicals such as phthalates, melamine and BPA are important factors in the etiology of CKD, especially in developing countries in which environmental pollution is prevalent. The pathogenic mechanisms by which most environmental nephrotoxicants induce CKD have been elucidated. Most studies on the pathogenic mechanisms of environmental pollutants have focused on systemic inflammation and oxidative stress, and the detailed mechanisms of the pathogenesis of specific kidney diseases are still not fully understood. Studying interactions between environment pollutants and genetic factors may help to elucidate disease susceptibility.

Most of the epidemiological evidence regarding the association between environmental pollution and kidney diseases discussed in this study comes from cross-sectional studies. To establish causal relationships and dose-response associations between exposure to environment pollutants and kidney disease for a wide range of exposure levels, more detailed longitudinal studies and also experimental designs with specific and quantified measurements of environmental exposure are required. It is crucial to implement environmental protection strategies and establish safe exposure levels of environmental pollutants, such as air quality standards. In summary, our findings support the need for regulatory strategies for the control of pollution and reduction or prevention of exposure to environmental health risks. Clinicians should be aware of the adverse renal effects induced by environmental exposure to pollutants. Detailed exposure assessments based on the sources of exposure for potential nephrotoxicants should be performed on a patient-by-patients basis.

\section{Acknowledgements}

This work was financially supported by the 
Research Center for Environmental Medicine, Kaohsiung Medical University, Kaohsiung, Taiwan from The Featured Areas Research Center Program within the framework of the Higher Education Sprout Project by the Ministry of Education (MOE) in Taiwan. This study is supported partially by Kaohsiung Medical University Research Center Grant (KMU-TC108A01).

\section{Competing Interests}

The authors have declared that no competing interest exists.

\section{References}

1. Nugent RA, Fathima SF, Feigl AB, Chyung D. The burden of chronic kidney disease on developing nations: a 21st century challenge in global health. Nephron. Clinical practice 2011;118(3): c269-77.

2. Levey AS, Coresh J, Balk E, et al. National Kidney Foundation practice guidelines for chronic kidney disease: evaluation, classification, and stratification. Ann Intern Med 2003; 139(2): 137-47.

3. Lunyera J, Mohottige D, Von Isenburg M, et al. CKD of Uncertain Etiology: A Systematic Review. CJASN 2016; 11(3): 379-85

4. Wen CP, Cheng TY, Tsai MK, et al. All-cause mortality attributable to chronic kidney disease: a prospective cohort study based on 462293 adults in Taiwan. Lancet 2008; 371(9631): 2173-82

5. Collins AJ, Foley RN, Chavers B, et al. US Renal Data System 2013 Annual Data Report. Am J Kidney Dis 2014; 63(1 Suppl): A7.

6. Afsar B, Elsurer Afsar R, Kanbay A, Covic A, Ortiz A, Kanbay M. Air pollution and kidney disease: review of current evidence. Clin Kidney J 2019; 12(1): 19-32.

7. Soderland P, Lovekar S, Weiner DE, Brooks DR, Kaufman JS. Chronic kidney disease associated with environmental toxins and exposures. Adv Chronic Kidney Dis 2010; 17(3): 254-64.

8. Scammell MK, Sennett CM, Petropoulos ZE, Kamal J, Kaufman JS. Environmental and Occupational Exposures in Kidney Disease. Semin Nephrol 2019; 39(3): 230-243.

9. Zheng LY, Sanders AP, Saland JM, Wright RO, Arora M. Environmental exposures and pediatric kidney function and disease: A systematic review. Environ Res 2017; 158: 625-648.

10. Kataria A, Trasande L, Trachtman H. The effects of environmental chemicals on renal function. Nat Rev Nephrol 2015; 11(10): 610-25.

11. Orr SE, Bridges CC. Chronic Kidney Disease and Exposure to Nephrotoxic Metals. Int J Mol Sci 2017; 18(5): 1039.

12. Prasad GV, Rossi NF. Arsenic intoxication associated with tubulointerstitial nephritis. Am J Kidney Dis 1995; 26(2): 373-6.

13. Sasaki A, Oshima Y, Fujimura A. An approach to elucidate potential mechanism of renal toxicity of arsenic trioxide. Exp Hematol 2007; 35(2): $252-62$.

14. Abdul KS, Jayasinghe SS, Chandana EP, Jayasumana C, De Silva PM. Arsenic and human health effects: A review. Environ Toxicol Pharmacol 2015; 40(3): 828-46.

15. Jomova $K$, Jenisova $Z$, Feszterova $M$, et al. Arsenic: toxicity, oxidative stress and human disease. J Appl Toxicol 2011; 31(2): 95-107.

16. Hsu LI, Hsieh FI, Wang YH, et al. Arsenic Exposure From Drinking Water and the Incidence of CKD in Low to Moderate Exposed Areas of Taiwan: A 14-Year Prospective Study. Am J Kidney Dis 2017; 70(6): 787-797.

17. Chen JW, Chen HY, Li WF, et al. The association between total urinary arsenic concentration and renal dysfunction in a community-based population from central Taiwan. Chemosphere 2011; 84(1): 17-24.

18. Cheng YY, Huang NC, Chang YT, et al. Associations between arsenic in drinking water and the progression of chronic kidney disease: A nationwide study in Taiwan. J Hazard Mater 2017; 321: 432-439.

19. Yang F, Yi X, Guo J, et al. Association of plasma and urine metals levels with kidney function: A population-based cross-sectional study in China. Chemosphere 2019; 226: 321-328.

20. Liu Y, Yuan Y, Xiao Y, et al. Associations of plasma metal concentrations with the decline in kidney function: A longitudinal study of Chinese adults. Ecotoxicol Environ Saf 2020; 189: 110006.

21. Madden EF, Fowler BA. Mechanisms of nephrotoxicity from metal combinations: a review. Drug Chem Toxicol 2000; 23(1): 1-12.

22. Jarup L, Rogenfelt A, Elinder CG, Nogawa K, Kjellstrom T. Biological half-time of cadmium in the blood of workers after cessation of exposure. Scand J Work Environ Health 1983; 9(4): 327-31.

23. Johri N, Jacquillet $G$, Unwin R. Heavy metal poisoning: the effects of cadmium on the kidney. Biometals 2010; 23(5): 783-92.
24. Hecht EM, Arheart $\mathrm{K}$, Lee DJ, Hennekens $\mathrm{CH}$, Hlaing WM. A cross-sectional survey of cadmium biomarkers and cigarette smoking. Biomarkers 2016; 21(5): 429-35.

25. Hecht EM, Arheart KL, Lee DJ, Hennekens CH, Hlaing WM. Interrelation of Cadmium, Smoking, and Cardiovascular Disease (from the National Health and Nutrition Examination Survey). Am J Cardiol 2016; 118(2): 204-9.

26. Richter PA, Bishop EE, Wang J, Swahn MH. Tobacco smoke exposure and levels of urinary metals in the U.S. youth and adult population: the National Health and Nutrition Examination Survey (NHANES) 1999-2004. Int J Environ Res Public Health 2009; 6(7): 1930-46.

27. Satarug S, Vesey DA, Gobe GC. Current health risk assessment practice for dietary cadmium: Data from different countries. Food Chem Toxicol 2017; 106(Pt A): 430-445.

28. Jarup L, Akesson A. Current status of cadmium as an environmental health problem. Toxicol Appl Pharmacol 2009; 238(3): 201-8.

29. Chaumont A, Nickmilder M, Dumont X, Lundh T, Skerfving S, Bernard A. Associations between proteins and heavy metals in urine at low environmental exposures: evidence of reverse causality. Toxicol Lett 2012; 210(3): 345-52.

30. Satarug S, Vesey DA, Gobe GC. Health Risk Assessment of Dietary Cadmium Intake: Do Current Guidelines Indicate How Much is Safe? Enviro Health Perspect 2017; 125(3): 284-288

31. Xu X, Nie S, Ding H, Hou FF. Environmental pollution and kidney diseases. Nature reviews. Nephrology 2018; 14(5): 313-324.

32. Wang D, Sun $\mathrm{H}, \mathrm{Wu} \mathrm{Y}$, et al. Tubular and glomerular kidney effects in the Chinese general population with low environmental cadmium exposure. Chemosphere 2016; 147: 3-8.

33. Eom SY, Seo MN, Lee YS, et al. Low-Level Environmental Cadmium Exposure Induces Kidney Tubule Damage in the General Population of Korean Adults. Arch Environ Contam Toxicol 2017; 73(3): 401-409.

34. Buser MC, Ingber SZ, Raines N, Fowler DA, Scinicariello F. Urinary and blood cadmium and lead and kidney function: NHANES 2007-2012. Int J Hyg Environ Health 2016; 219(3): 261-7.

35. Navas-Acien A, Tellez-Plaza M, Guallar E, et al. Blood cadmium and lead and chronic kidney disease in US adults: a joint analysis. Am J Epidemiol 2009; 170(9): 1156-64.

36. Madrigal JM, Ricardo AC, Persky V, Turyk M. Associations between blood cadmium concentration and kidney function in the U.S. population: Impact of sex, diabetes and hypertension. Enviro Res 2019; 169: 180-188.

37. Myong JP, Kim HR, Baker D, Choi B. Blood cadmium and moderate-to-severe glomerular dysfunction in Korean adults: analysis of KNHANES 2005-2008 data. Int Arch Occup Environ Health 2012; 85(8): 885-93.

38. Kim NH, Hyun YY, Lee KB, et al. Environmental heavy metal exposure and chronic kidney disease in the general population. J Korean Med Sci 2015; 30(3): 272-7.

39. Liu G, Wang ZK, Wang ZY, Yang DB, Liu ZP, Wang L. Mitochondrial permeability transition and its regulatory components are implicated in apoptosis of primary cultures of rat proximal tubular cells exposed to lead. Arch Toxicol 2016; 90(5): 1193-209.

40. Navarro-Moreno LG, Quintanar-Escorza MA, Gonzalez S, et al. Effects of lead intoxication on intercellular junctions and biochemical alterations of the renal proximal tubule cells. Toxicol In Vitro 2009; 23(7): 1298-304

41. Weidemann DK, Weaver VM, Fadrowski JJ. Toxic environmental exposures and kidney health in children. Pediatr Nephrol 2016; 31(11): 2043-54.

42. Ekong EB, Jaar BG, Weaver VM. Lead-related nephrotoxicity: a review of the epidemiologic evidence. Kidney Int 2006; 70(12): 2074-84.

43. Nowack R, Wiecek A, Ritz E. Lead and hypertension. Contrib Nephrol 1992; 100: 25-34

44. Said S, Hernandez GT. Environmental exposures, socioeconomics, disparities, and the kidneys. Adv Chronic Kidney Dis 2015; 22(1): 39-45.

45. Lai LH, Chou SY, Wu FY, Chen JJ, Kuo HW. Renal dysfunction and hyperuricemia with low blood lead levels and ethnicity in community-based study. Sci Total Environ 2008; 401(1-3): 39-43

46. Weaver VM, Griswold M, Todd AC, et al. Longitudinal associations between lead dose and renal function in lead workers. Environ Res 2009; 109(1): 101-7.

47. Muntner P, Menke A, DeSalvo KB, Rabito FA, Batuman V. Continued decline in blood lead levels among adults in the United States: the National Health and Nutrition Examination Surveys. Arch Internal Med 2005; 165(18): 2155-61.

48. Kim Y, Lee BK. Associations of blood lead, cadmium, and mercury with estimated glomerular filtration rate in the Korean general population: analysis of 2008-2010 Korean National Health and Nutrition Examination Survey data. Environ Res 2012; 118: 124-9.

49. Yu CC, Lin JL, Lin-Tan DT. Environmental exposure to lead and progression of chronic renal diseases: a four-year prospective longitudinal study. JASN 2004; 15(4): 1016-22.

50. Harari F, Sallsten G, Christensson A, et al. Blood Lead Levels and Decreased Kidney Function in a Population-Based Cohort. Am J Kidney Dis 2018; 72(3): 381-389.

51. Hara A, Yang WY, Petit T, et al. Incidence of nephrolithiasis in relation to environmental exposure to lead and cadmium in a population study. Environ Res 2016; 145: 1-8.

52. Sun $Y$, Zhou Q, Zheng J. Nephrotoxic metals of cadmium, lead, mercury and arsenic and the odds of kidney stones in adults: An exposure-response analysis of NHANES 2007-2016. Environ Int 2019; 132: 105115. 
53. Chan TY. Inorganic mercury poisoning associated with skin-lightening cosmetic products. Clin Toxicol 2011; 49(10): 886-91.

54. Zalups RK. Early aspects of the intrarenal distribution of mercury after the intravenous administration of mercuric chloride. Toxicology 1993; 79(3): 215-28.

55. Zalups RK, Koropatnick J. Temporal changes in metallothionein gene transcription in rat kidney and liver: relationship to content of mercury and metallothionein protein. J Pharmacol and Exp Ther 2000; 295(1): 74-82.

56. Omata S, Sato M, Sakimura K, Sugano H. Time-dependent accumulation of inorganic mercury in subcellular fractions of kidney, liver, and brain of rats exposed to methylmercury. Arch Toxicol 1980;44(4): 231-41.

57. Bjorklund G, Dadar M, Mutter J, Aaseth J. The toxicology of mercury: Current research and emerging trends. Environ Res 2017; 159: 545-554.

58. Hodgson S, Nieuwenhuijsen MJ, Elliott P, Jarup L. Kidney disease mortality and environmental exposure to mercury. Am J Epidemiol 2007 ;165(1): $72-7$.

59. Miller S, Pallan S, Gangji A, Lukic D, Clase CM. Mercury-associated nephrotic syndrome: a case report and systematic review of the literature. Am J Kidney Dis 2013; 62(1): 135-8.

60. Nuyts GD, Van Vlem E, Thys J, et al. New occupational risk factors for chronic renal failure. Lancet 1995; 346(8966): 7-11.

61. Rodriguez LH, Rodriguez-Villamizar LA, Florez-Vargas O, Fiallo YV, Ordonez A, Gutierrez MD. No effect of mercury exposure on kidney function during ongoing artisanal gold mining activities in Colombia. Toxicol Ind Health 2017; 33(1): 67-78.

62. Roszell LE, Hahn FF, Lee RB, Parkhurst MA. Assessing the renal toxicity of Capstone depleted uranium oxides and other uranium compounds. Health Phys 2009; 96(3): 343-51.

63. Zamora ML, Tracy BL, Zielinski JM, Meyerhof DP, Moss MA. Chronic ingestion of uranium in drinking water: a study of kidney bioeffects in humans. Toxicol Sci 1998; 43(1): 68-77.

64. Kurttio $\mathrm{P}$, Harmoinen $\mathrm{A}$, Saha $\mathrm{H}$, et al. Kidney toxicity of ingested uranium from drinking water. Am J Kidney Dis 2006; 47(6): 972-82.

65. Okaneku J, Vearrier D, McKeever R, Lasala G, Greenberg MI. Urine uranium concentrations and renal function in residents of the United States--2001 to 2010. Clin Toxicol 2015; 53(10): 931-4.

66. Arzuaga X, Rieth SH, Bathija A, Cooper GS. Renal effects of exposure to natural and depleted uranium: a review of the epidemiologic and experimental data. J Toxicol Environ Health B Crit Rev 2010; 13(7-8): 527-45.

67. Wu W, Zhang K, Jiang S, et al. Association of co-exposure to heavy metals with renal function in a hypertensive population. Environ Int 2018; 112: 198-206

68. Selden AI, Lundholm C, Edlund B, et al. Nephrotoxicity of uranium in drinking water from private drilled wells. Environ Res 2009; 109(4): 486-94

69. Weaver VM, Vargas GG, Silbergeld EK, et al. Impact of urine concentration adjustment method on associations between urine metals and estimated glomerular filtration rates (eGFR) in adolescents. Environ Res 2014; 132: 226-32.

70. Ghio AJ, Carraway MS, Madden MC. Composition of air pollution particles and oxidative stress in cells, tissues, and living systems. J Toxicol Environ Health B Crit Rev 2012; 15(1): 1-21.

71. Liu B, Fan D, Huang F. Relationship of chronic kidney disease with major air pollutants - A systematic review and meta-analysis of observational studies. Environ Toxicol Pharmacol 2020; 76: 103355

72. Wu MY, Lo WC, Chao CT, Wu MS. Chiang CK. Association between air pollutants and development of chronic kidney disease: A systematic review and meta-analysis. Sci Total Environ 2020; 706: 135522.

73. Bowe B, Xie Y, Li T, Yan Y, Xian H, Al-Aly Z. Associations of ambient coarse particulate matter, nitrogen dioxide, and carbon monoxide with the risk of kidney disease: a cohort study. Lancet Planet Health 2017; 1(7): e267-e276.

74. Bowe B, Xie Y, Li T, Yan Y, Xian H, Al-Aly Z. Particulate Matter Air Pollution and the Risk of Incident CKD and Progression to ESRD. JASN 2018; 29(1): 218-230.

75. Bragg-Gresham J, Morgenstern H, McClellan W, et al. County-level air quality and the prevalence of diagnosed chronic kidney disease in the US Medicare population. PloS One 2018: 13(7): e0200612.

76. Mehta AJ, Zanobetti A, Bind MA, et al. Long-Term Exposure to Ambient Fine Particulate Matter and Renal Function in Older Men: The Veterans Administration Normative Aging Study. Environ Health Perspect 2016; 124(9): 1353-60

77. Chan TC, Zhang Z, Lin BC, et al. Long-Term Exposure to Ambient Fine Particulate Matter and Chronic Kidney Disease: A Cohort Study. Environ Health Perspect 2018; 126(10): 107002

78. Kim HJ, Min JY, Seo YS, Min KB. Association between exposure to ambient air pollution and renal function in Korean adults. Ann Occup Environ Med 2018; 30: 14 .

79. Yang YR, Chen YM, Chen SY, Chan CC. Associations between Long-Term Particulate Matter Exposure and Adult Renal Function in the Taipei Metropolis. Environ Health Perspect 2017; 125(4): 602-607.

80. Ran J, Sun S, Han L, et al. Fine particulate matter and cause-specific mortality in the Hong Kong elder patients with chronic kidney disease. Chemosphere 2020; 247: 125913.

81. Jung J, Park JY, Kim YC, et al. Clinical Research Center For End-Stage Renal Disease Crc For Esrd, I., Long-Term Effects of Air Pollutants on Mortality Risk in Patients with End-Stage Renal Disease. Int J Environ Research Public Health 2020; 17(2):546.
82. Nemmar A, Al-Salam S, Zia S, Yasin J, Al Husseni I, Ali BH. Diesel exhaust particles in the lung aggravate experimental acute renal failure. Toxicol Sci 2010; 113(1): 267-77.

83. Nemmar A, Karaca T, Beegam S, et al. Prolonged Pulmonary Exposure to Diesel Exhaust Particles Exacerbates Renal Oxidative Stress, Inflammation and DNA Damage in Mice with Adenine-Induced Chronic Renal Failure. Cell Physiol Biochem 2016; 38(5): 1703-13.

84. Wu MT, $\mathrm{Wu} \mathrm{CF}, \mathrm{Wu} J \mathrm{~J}$, et al. The public health threat of phthalate-tainted foodstuffs in Taiwan: the policies the government implemented and the lessons we learned. Environ Int 2012; 44: 75-9.

85. Wu MT, $\mathrm{Wu} \mathrm{CF}, \mathrm{Chen} \mathrm{BH}$, et al. Intake of phthalate-tainted foods alters thyroid functions in Taiwanese children. PloS One 2013; 8(1): e55005.

86. Wu $\mathrm{CF}$, Chen $\mathrm{BH}$, Shiea J, et al. Temporal changes of urinary oxidative metabolites of di(2-ethylhexyl)phthalate after the 2011 phthalate incident in Taiwanese children: findings of a six month follow-up. Environ Sci Technol 2013; 47(23): 13754-62.

87. Wu CF, Chang-Chien GP, Su SW, Chen BH, Wu MT. Findings of 2731 suspected phthalate-tainted foodstuffs during the 2011 phthalates incident in Taiwan. J Formos Med Assoc 2014; 113(9): 600-5.

88. Tsai $\mathrm{HJ}, \mathrm{Chen} \mathrm{BH}, \mathrm{Wu} \mathrm{CF}$, et al. Intake of phthalate-tainted foods and microalbuminuria in children: The 2011 Taiwan food scandal. Environ Int 2016; 89-90: 129-37.

89. Tsai HJ, Wu CF, Tsai YC, et al. Intake of Phthalate-tainted Foods and Serum Thyroid Hormones in Taiwanese Children and Adolescents. Sci Rep 2016; 6: 30589.

90. Wu CF, Hsiung CA, Tsai $\mathrm{HJ}$, et al. Interaction of melamine and di-(2-ethylhexyl) phthalate exposure on markers of early renal damage in children: The 2011 Taiwan food scandal. Environ Pollut 2018, 235, 453-461.

91. Colacino JA, Harris TR, Schecter A. Dietary intake is associated with phthatate body burden in a nationally representative sample. Environ Health Perspect 2010; 118(7): 998-1003.

92. Rudel RA, Gray JM, Engel CL, et al. Food packaging and bisphenol A and bis(2-ethyhexyl) phthalate exposure: findings from a dietary intervention. Environ Health Perspect 2011; 119(7): 914-20.

93. Trasande L, Sathyanarayana S, Trachtman H. Dietary phthalates and low-grade albuminuria in US children and adolescents. CJASN 2014; 9(1): $100-9$.

94. Chen J, Zhou X, Zhang $\mathrm{H}$, et al. Association between urinary concentration of phthalate metabolites and impaired renal function in Shanghai adults. Environ Pollut 2019; 245: 149-162.

95. Chen I, Shi X, Zhou X, et al. Renal function and the exposure to melamine and phthalates in Shanghai adults. Chemosphere 2020; 246: 125820.

96. Kang H, Kim S, Lee G, et al. Urinary metabolites of dibutyl phthalate and benzophenone- 3 are potential chemical risk factors of chronic kidney function markers among healthy women. Environ Int 2019; 124: 354-360.

97. Mengozzi A, Carli F, Biancalana E, et al. Phthalates Exposure as Determinant of Albuminuria in Subjects With Type 2 Diabetes: A Cross-Sectional Study. J Clin Endocrinol Metab 2019; 104(5): 1491-1499.

98. Malits J, Attina TM, Karthikraj R, et al. Renal Function and exposure to Bisphenol A and phthalates in children with Chronic Kidney Disease. Environ Res 2018; 167: 575-582

99. Ingelfinger JR. Melamine and the global implications of food contamination. $N$ Eng J Med 2008; 359(26): 2745-8

100. Panuwet P, Nguyen JV, Wade EL, D'Souza PE, Ryan PB, Barr DB. Quantification of melamine in human urine using cation-exchange based high performance liquid chromatography tandem mass spectrometry. J Chromatogr B Analyt Technol Biomed Life Sci 2012; 887-888: 48-54.

101. Lin YT, Tsai MT, Chen YL, et al. Can melamine levels in 1-spot overnight urine specimens predict the total previous 24-hour melamine excretion level in school children? Clin Chim Acta 2013; 420: 128-33.

102. Wu CF, Liu CC, Chen BH, et al. Urinary melamine and adult urolithiasis in Taiwan. Clin Chim Acta 2010; 411 (3-4): 184-9.

103. Liu $\mathrm{CC}, \mathrm{Wu} \mathrm{CF}$, Chen $\mathrm{BH}$, et al. Low exposure to melamine increases the risk of urolithiasis in adults. Kidney Int 2011; 80(7): 746-52.

104. Wu CF, Peng CY, Liu CC, et al. Ambient Melamine Exposure and Urinary Biomarkers of Early Renal Injury. JASN 2015; 26(11): 2821-9.

105. Liu CC, Hsieh TJ, Wu CF, et al.Urinary melamine excretion and increased markers of renal tubular injury in patients with calcium urolithiasis: A cross-sectional study. Environ Pollut 2017; 231(Pt 2): 1284-1290.

106. Tsai YC, Wu CF, Liu CC, et al. Urinary Melamine Levels and Progression of CKD. CJASN 2019; 14(8): 1133-1141.

107. Guo J, Wu C, Zhang J, et al. Associations of melamine and cyanuric acid exposure with markers of kidney function in adults: Results from NHANES 2003-2004. Environ Int 2020; 141: 105815

108. Sathyanarayana S, Flynn JT, Messito MJ, et al. Melamine and cyanuric acid exposure and kidney injury in US children. Environ Res 2019; 171: 18-23.

109. Liu CC, Hsieh TJ, Wu CF, et al. Interrelationship of environmental melamine exposure, biomarkers of oxidative stress and early kidney injury. J Hazard Mater 2020; 396: 122726

110. Hsieh TJ, Hsieh PC, Tsai YH, et al. Melamine induces human renal proximal tubular cell injury via transforming growth factor-beta and oxidative stress. Toxicol Sci 2012; 130(1): 17-32.

111. Shankar A, Teppala S. Urinary bisphenol A and hypertension in a multiethnic sample of US adults. J Environ Public Health 2012; 2012: 481641. 
112. He Y, Miao M, Herrinton LJ, et al. Bisphenol A levels in blood and urine in a Chinese population and the personal factors affecting the levels. Environ Res 2009; 109(5): 629-33.

113. Trasande L, Attina TM, Trachtman H. Bisphenol A exposure is associated with low-grade urinary albumin excretion in children of the United States. Kidney Int 2013; 83(4): 741-8.

114. Li M, Bi Y, Qi L, et al. Exposure to bisphenol A is associated with low-grade albuminuria in Chinese adults. Kidney Int 2012; 81(11): 1131-9.

115. You L, Zhu X, Shrubsole MJ, et al. Renal function, bisphenol A, and alkylphenols: results from the National Health and Nutrition Examination Survey (NHANES 2003-2006). Environ Health Perspect 2011; 119(4): 527-33.

116. Hu J, Yang S, Wang Y, et al. Serum bisphenol A and progression of type 2 diabetic nephropathy: a 6-year prospective study. Acta Diabetol 2015; 52(6); 1135-41.

117. Hu J, Wang Y, Xiang X, et al. Serum bisphenol A as a predictor of chronic kidney disease progression in primary hypertension: a 6-year prospective study. J Hypertens 2016; 34(2): 332-7. 